END OF LIFE

\title{
Medical ethics, logic traps, and game theory: an illustrative tale of brain death
}

\section{J E Riggs}

J Med Ethics 2004;30:359-361. doi: 10.1136/jme.2002.002667

Decision making and choices are frequent themes in medical ethics. Game theory is based upon modelled decision making. Game theory, and associated logic traps, may have relevance to the clinical practice of medicine and medical ethics. The "prisoner's dilemma" is one logic trap from game theory in which "rational" decision making on the part of participating individuals can lead to "suboptimal" situations. An example of such a situation involving brain death is presented and discussed from the perspective of the prisoner's dilemma.

A frequent theme in medical ethics is that of making decisions and choices. Indeed, the patient-physician relationship can be viewed as a complex interaction based upon decisions and choices. Although the psychology and inherent biases involved in making decisions and choices have been delineated, ${ }^{1-3}$ these inherent limitations have not routinely entered the medical ethics curriculum for healthcare professionals.

Game theory is based upon modelled decision making. ${ }^{4}$ As such, game theory may have relevance to medical ethics. Game theory was developed and intensively studied in the 1950s and 1960s in response to the Cold War to assist national command authorities in policy development and decision making strategies. ${ }^{6}$ With the advent of nuclear weapons and a runaway arms race, the potential consequences of a nuclear confrontation between the world's two superpowers were unimaginable. National command authorities became interested in understanding how rational decision making could lead to irrational actions. The "prisoner's dilemma" is a famous logic trap from game theory in which rational decision making on the part of participating individuals can lead to an irrational situation.

\section{THE PRISONER'S DILEMMA}

The prisoner's dilemma is often presented in the following manner. ${ }^{7}$ Two individuals (prisoners A and B) are arrested for a crime they committed together. They are questioned separately and offered the same deal. If one confesses and the other doesn't confess, the one who confesses will receive a suspended sentence for providing state's evidence while the other will receive an extended prison sentence (for example, 10 years). If both confess, they will each receive a shortened prison sentence (for example, three years). If neither confesses, both are likely to only be convicted of a lesser crime and receive a minimal prison sentence (for example, one year). What are the prisoners likely to decide to do? The answer is best understood by constructing a two by two decision table (table 1). Prisoner A will most logically consider his or her best course of action based upon prisoner B's possible decisions. For example, if prisoner B decides to confess, prisoner A's most rational decision is to confess (see table 1, A gets three years if he or she confesses versus 10 years if choosing not to confess). If prisoner B decides not to confess, prisoner A's most logical decision is also to confess ( see table 1 , A gets 0 years if he or she confesses versus 1 year if choosing not to confess). Thus, no matter what prisoner $\mathrm{B}$ decides, prisoner A logically concludes that the best decision is to confess. Analogously, no matter what prisoner A decides, prisoners B's most logical decision is also to confess. Consequently, rational reasoning will result in both prisoners spending three years in prison versus only one year in prison had both decided to act "irrationally" and not confess; hence, the logic trap associated with the prisoner's dilemma.

\section{ILLUSTRATIVE MEDICAL ETHICS SCENARIO}

A neurologist in the USA receives a call from a state politician describing a distressed mother (and constituent) who is far from home and who has been told that her 19 year old daughter (who is on a respirator) is "brain dead". The politician tells the neurologist that the mother would feel more comfortable if the diagnosis was confirmed by a home state neurologist before the daughter was disconnected from the respirator. The politician has arranged for the state to transport the girl home and requests that the neurologist accept the girl in transfer to confirm the diagnosis of brain death. The neurologist agrees to accept the patient. The next day, the girl is sent by chartered jet. The neurologist examines the girl and finds no clinical evidence of cortical or brainstem function, obtains an electroencephalogram which shows no electrocerebral activity, and confirms the diagnosis of brain death. The neurologist dutifully records his findings and impression in the hospital chart. The neurologist informs the mother of her daughter's diagnosis and suggests that the respirator be discontinued. The mother pleads not to disconnect her daughter until her husband has had a chance to get to the hospital. The mother explains that there was not room on the small jet for her husband and that he had to drive home. The neurologist agrees to wait for the father. The father arrives the next day, immediately demands of the neurologist that under no circumstances is his daughter to be removed from the respirator and threatens legal action.

\section{DISCUSSION}

What does the illustrative scenario have to do with game theory, the prisoner's dilemma, or medical ethics? In game theory, the "prisoner's dilemma" is a two person non-zerosum game. ${ }^{4}$ The prisoner's dilemma is non-zero-sum because a gain for one participant does not necessarily reflect a loss for the other participant. In this regard, the "patientphysician relationship" can also be viewed as a two person non-zero-sum game. (In the described scenario, the parents are surrogates for the patient.) In clinical practice, there are actually many two person games going on simultaneously; for example, patient-physician, physician-family, physicianhospital, and physician-insurance carrier. Moreover, the prisoner's dilemma is actually an idealised and unrealistic 


\begin{tabular}{l}
$\begin{array}{l}\text { Table } 1 \\
\text { Prison sentences (in years) of two } \\
\text { prisoners (A, B) as a result of confessing or not } \\
\text { confessing according to the "prisoner's } \\
\text { dilemma" scenario described in the paper }\end{array}$ \\
\begin{tabular}{l} 
Prisoner B \\
\cline { 2 - 2 } Confess
\end{tabular} \\
$\begin{array}{l}\text { Prisoner A } \\
\text { Confess }\end{array}$ \\
$\begin{array}{l}\text { Not confess } \\
\text { 3, } 3\end{array}$ \\
\hline
\end{tabular}

two person non-zero-sum game in which the participants know the "pay-offs" associated with their decisions. In reality, few decisions are made with fore knowledge of the actual benefits and risks associated with those decisions. Typically, decisions are made with only estimates of the benefits and risks associated with those decisions. In game theory, the pay-offs shown in table 1 are best thought of as "utility functions". A utility function is a quantification of a preference with respect to some object, outcome, or pay-off. ${ }^{4}$ Utility functions vary from individual to individual. For example, if a poor man were offered the choice between a guaranteed pay-off of $\$ 1000000$ or a 50-50 chance of a $\$ 5000000$ or $\$ 0$ pay-off, studies have shown that he will take the guaranteed pay-off of $\$ 1000000$ despite the fact that average utility of the gamble is $\$ 2500000 . .^{1-4} \mathrm{~A}$ billionaire, on the other hand, is much more likely to take the gamble.

In the prisoner's dilemma, the logic trap occurs because each prisoner adopted a limited perspective that involves only considering the possible decisions made by the other prisoner. In practice, situations that mimic the prisoner's dilemma are typically constructed or framed in a manner that encourages a limited perspective on the part of the participants. What was the limited perspective with the neurologist's first decision to accept the patient in transfer? The neurologist made a purely political decision by only considering his decision in the light of what he thought the politician would have done had he refused to accept the patient. The neurologist thought that had he refused, the politician's next call would have been to the dean of the medical school. The politician had already arranged for the state to pay for the girl's transportation home and was unlikely to accept a decision by the neurologist not to accept the girl in transfer. The neurologist believed that refusing to accept was not a viable or rational option. The neurologist felt that no additional information or broadened perspective was necessary for him to make a seemingly simple and logical decision. He did not call the neurologist who had seen this girl in the other state. Had he done this, the neurologist would have learned that the girl had already been brain dead for four days and that the family had also refused removal of life support and threatened legal action.

What was the limited perspective of the neurologist's second decision to delay removing life support until the girl's father arrived? The neurologist made a purely personal and emotional decision based solely by considering how he would have felt if it were his daughter who was brain dead. The neurologist thought that had he refused, he would be behaving in a manner that would be inconsistent with how he would want to be treated in a similar situation. The neurologist again felt that no additional information or broadened perspective was necessary for him to make another seemingly simple and logical decision.

After the father arrived, the neurologist felt that an appropriate two by two decision table for the pay-offs for the neurologist and the parents with regard to disconnecting or not disconnecting the young girl from the respirator might look something like those displayed in table 2. From the neurologist's perspective, continuing to treat a brain dead individual had no positive utility. Moreover, the neurologist could not imagine any positive utility from the parents' perspective associated with not disconnecting the brain dead girl from the respirator. As table 2 indicates, the neurologist felt that disconnecting the brain dead girl from the respirator was the only reasonable decision.

The neurologist soon learned, however, that the "real" reason for the parents' need to prevent removal of their daughter from the respirator was to keep their daughter "alive" at all costs until a "miracle" had been performed. The parents practised a very fundamentalist Christian religion. Their young daughter had been travelling with a man to whom she was not married. From the parents' perspective, if their daughter died, she would die in a state of sin and her soul would be condemned to hell for all eternity. The parents believed that prayer and a miracle by a loving and forgiving God could give their daughter a new brain and a second chance at salvation.

The neurologist realised that the two by two decision table for the pay-offs from the parents' perspective actually looked something like shown in table 3. From the parents' perspective, the negative utility associated with disconnecting the respirator was so great that the only reasonable decision was to leave their daughter on the respirator.

The neurologist realised that he was now involved in the treatment of a body which had been legally declared dead for six days. (Insurance companies do not like to pay for medically non-indicated, unnecessary, and inappropriate treatment.) Like most moral and ethical issues, mere recognition of the dilemma does not provide a solution. Indeed, in certain situations, there are be no solutions to the prisoner's dilemma. ${ }^{8}$ The neurologist realised that he would not be able to convince the parents that table 2, and not table 3, was the more accurate representation of reality. The parents, however, had also suggested to the neurologist a means to the resolution of this medical ethics dilemma.

\section{ILLUSTRATIVE MEDICAL ETHICS SCENARIO POSTSCRIPT}

The neurologist agreed with the father that legal action was necessary. The neurologist suggested that the father immediately consult an attorney and try to get a court order requiring the neurologist not to disconnect his daughter from the respirator. The neurologist then notified the hospital's attorneys of the situation. The father's attorney, the hospital's attorneys, and the local court all agreed that no life support measures were indicated and that the girl should be removed from the respirator. The family reluctantly recognised the futility of their situation and agreed that the respirator could

Table 2 Hypothetical utility pay-offs for the neurologist and the parents of the young girl described in the paper as a result of disconnecting the respirator or not disconnecting the respirator (from the perspective of the neurologist)

\begin{tabular}{lrr}
\hline & \multicolumn{2}{l}{ Parents } \\
\cline { 2 - 3 } & Disconnect & Not disconnect \\
\hline Neurologist & 10,10 & $10,-50$ \\
Disconnect & $-100,10$ & $-100,-50$ \\
Not disconnect & & \\
\hline
\end{tabular}


Table 3 Hypothetical utility pay-offs for the neurologist and the parents of the young girl described in the paper as a result of disconnecting the respirator or not disconnecting the respirator (from the perspective of the parents)

\begin{tabular}{lll}
\hline & Parents \\
\cline { 2 - 3 } & Disconnect & Not disconnect \\
\hline Neurologist & $0,-1000$ & 0,1000 \\
Disconnect & $0,-1000$ & 0,1000 \\
\hline Not disconnect & $0,-$ \\
\hline
\end{tabular}

be removed. This legal activity consumed three more days (the girl had now been brain dead and on a respirator for nine days following a ruptured cerebral aneurysm). At this point, the parents called the neurologist to inform him that their desired "miracle" had occurred. Their daughter was now "purposefully" moving her extremities. Sure enough, the girl had complex spontaneous and reflex movements of all four extremities that could be elicited by the slightest touch. The neurologist spent one more day obtaining another electroencephalogram with the girl paralysed and explaining the occurrence of complex spontaneous and reflex movements in brain dead patients to the parents and hospital staff. ${ }^{9-11}$ Ten days after initially being declared brain dead, the teenage girl's body was disconnected from the respirator.

The neurologist's decision table (table 2) analysis of the situation was founded on medical utility and the parents' decision table (table 3 ) analysis of the situation was founded on religious utility. The two perspectives were not likely to be reconciled in this situation. The parents, by threatening legal action, had indicated their potential willingness to accept legal utility. The neurologist was able to use this acceptable common perspective to "force" a resolution to this medical ethics dilemma. Game theory is an approach to visualising ethical issues utilising different perspectives. Game theory can have utility in dealing with some ethical issues encountered in the clinical practice of medicine.

As an additional comment, the very concept of brain death continues to be a challenged and debated issue. ${ }^{12}{ }^{13}$ The ethical issues surrounding transplantation, fetal tissue research, and cloning will continue to make the concept of brain death an important societal issue. This manuscript, however, does not attempt to enter into this debate.

Finally, it is important to recognise the inherent limitations of any frame of reference. For example, the prisoner's dilemma is a hypothetical construct and, as such, does not perfectly describe the ethical dilemma in this case of brain death. Moreover, no claim is made or implied that game theory will help resolve any ethical dilemma. Indeed, despite decades of study, game theory has not solved any of the world's political or economic problems. Such aspirations, however, were never the goal of game theory. The goal of game theory rather is to describe frames of reference from which problems, issues, or dilemmas can be better understood or appreciated. Frustration with game theory, or any other model, will undoubtedly occur when the utility of those frames of references are continually changing in evolving cultures and societies.

Correspondence to: Dr J E Riggs, Department of Neurology, PO Box 9180, West Virginia University Health Sciences Center, Morgantown, WV 26506-9180, USA; jriggs@wvu.edu

Revised version received 15 February 2003

Accepted for publication 28 February 2003

\section{REFERENCES}

1 Arrow KJ. Social choice and individual values. New Haven: Yale University Press, 1951.

2 Black D. The theory of committees and elections. Cambridge: Cambridge University Press, 1958

3 Kahneman D, Slovic P, Tversky A. Judgement under uncertainty: heuristics and biases. Cambridge: Cambridge University Press, 1982.

4 Davis MD. Game theory, a nontechnical introduction. Mineola: Dover Publications, Inc, 1970.

5 Luce RD, Raiffa H. Games and decisions, introduction and critical survey. Mineola: Dover Publications, Inc, 1989

6 Poundstone W. Prisoner's dilemma. John von Neumann, game theory, and the puzzle of the bomb. New York: Doubleday, 1992.

7 Taylor AD. Mathematics and politics. Strategy, voting, power and proof. New York: Springer, 1995.

8 Lorberbaum JP, Bohning DE, Shastri A, et al. Are there really no evolutionarily stable strategies in the iterated prisoner's dilemma? J Theor Biol 2002;214:155-69.

9 Ivan LP. Spinal reflexes in cerebral death. Neurology 1973;23:650-2.

10 Ropper AH. Unusual spontaneous movements in brain-dead patients. Neurology 1984;34:1089-92.

11 Saposnik G, Bueri JA, Maurino J, et al. Spontaneous and reflex movements in brain death. Neurology 2000;54:221-3.

12 Truog RD. Is it time to abandon brain death? Hastings Cent Rep 1997;27:29-37.

13 Bernat JL. A defense of the whole-brain concept of death. Hastings Cent Rep 1998;28:14-23. 